\section{D \\ Observatório da Jurisdiçãc Constitucional}

Observatório da Jurisdição Constitucional. Ano 6, no. 2, jul./dez. 2013. ISSN 1982-4564.

\title{
Aceleração da democracia brasileira?
}

Rodrigo de Bittencourt Mudrovitsch ${ }^{*}$

Resumo: $\mathrm{O}$ artigo analisa o estágio atual da democracia brasileira com o escopo de demonstrar que representa problema relevante a ausência de arenas de dissenso na sociedade civil. São pressupostos do estudo as percepções de que: (a) diferentemente do que ocorre com outras patologias sociais, a criação de canal de comunicação entre as instituições e a sociedade civil depende de efetivos experimentalismos democráticos que não podem ser realizados a partir da jurisdição constitucional ou por exclusivo intermédio dela; e (b) não se tem revelado eficaz no Brasil a política de laissez-faire estatal em relação à promoção social da cidadania. Ao final, o artigo explicita o conceito de democracia que essa proposta de aceleração democrática deve construir no plano teórico, especialmente em razão da dificuldade de explicitação do conteúdo de uma agenda de incremento da qualidade dos governos representativos democráticos modernos.

Palavras-chave: Aceleração democrática. Arenas de dissenso moral. Promoção social da cidadania. Qualidade de governos representativos.

\begin{abstract}
This Essay analyses the current stage of democracy in Brazil, with the purpose of demonstrating that the absence of social arenas of dissent represents a relevant pathology. It assumes that (a) unlike other social problems, the absence of social arenas cannot be solved by the Courts; and (b) the Brazilian policy of laissez-faire regarding the promotion of a citizenship agenda has not yet proved its efficiency. This Essay also proposes theoretical patterns for the development of a concept of democracy that justifies the proposition of improving the quality of representative governments by the development of social arenas of dissent.
\end{abstract}

Keywords: Democratic acceleration. Social arenas of dissent. Citizenship agenda. Quality of representative governments.

\footnotetext{
* Doutorando em Direito Constitucional pelo Departamento de Direito do Estado da USP. Mestre em Direito, Estado e Constituição pela UnB. Professor do IDP, da EDB e Professor voluntário da UnB na área de Direito Público.
} 


\section{SUMÁRIO}

1. Introdução;

2. Esferas públicas políticas como arenas de dissenso moral;

3. $\mathrm{O}$ caso brasileiro;

4. Da solidariedade espontânea para a solidariedade forçada: superação da política de laissezfaire estatal quanto à cidadania democrática;

5. As metamorfoses da democracia: agenda de pensamento teórico;

Referências bibliográficas.

\section{Introdução}

Em entrevista concedida à Revista Veja em 3 de agosto de 1977, Fernando Henrique Cardoso atestou, de maneira taxativa, que, "substantivamente, nunca houve democracia no Brasil" (2010:25). Quase 30 anos depois, no posfácio da obra que escreveu a respeito de sua experiência como Presidente do Brasil, Fernando Henrique Cardoso revelou que, a despeito de toda a evolução ocorrida nos anos anteriores, ainda mantinha visão pessimista sobre o estágio de desenvolvimento da democracia no país. Afirmou, nesse sentido, que "o que me decepciona é ver o tempo que custou para o país obter os resultados que alcançamos, tão longe ainda do necessário" (2012:673). Algum conceito de democracia substantiva possivelmente também era o que Charles Tilly tinha em mente ao sustentar a irrelevância prática e teórica da previsão da Constituição de 1996 do Cazaquistão que qualificava como democrático o regime político praticado naquele país (2007:1-5). As visões de Fernando Henrique Cardoso e Charles Tilly exemplificam o fato, reconhecido por Adam Przeworski, de que os teóricos sociais geralmente embutem no conceito de democracia o contrário de tudo aquilo repudiam nos regimes autoritários (2010:xii). Isso faz com que seja mais comum encontrar fórmulas de condução de processos de democratização do que agendas voltadas ao incremento da qualidade de democracias consolidadas. De fato, tornou-se simples saber o que a democracia não representa e extremamente difícil compreender o contrário.

Nas hipóteses em que a discussão a respeito da qualidade de determinada democracia em si é travada academicamente, a análise teórica costuma se circunscrever aos planos: (a) cidadão, voltado à verificação do grau de garantia prática de conceitos substantivos de direitos civis e sociais; e (b) institucional, direcionada a análises que, ao mesmo tempo em que equiparam democracia, governo representativo e sufrágio universal, objetivam desenvolver 
arranjos que permitam a maior participação popular nas decisões políticas, ou, muitas vezes, maior identidade entre representantes e representados.

No âmbito da análise jurídica, é pressuposto do breve estudo que será desenvolvido adiante o reconhecimento da necessidade de mudança no ponto de partida das teorias constitucionais dominantes na atualidade. Isso porque, conforme já diagnosticado por Roberto Mangabeira Unger (2004a), a obsessão atual dos juristas com a pergunta "como os juízes devem julgar?" representa o fracasso da doutrina constitucional em passar do momento da preocupação com o gozo dos direitos para o passo do experimentalismo institucional, que é necessário para que o direito não perca relevância como instrumento de transformação social. Nesse sentido, quando visualiza o jurista como seu agente primário, a teoria constitucional dominante na atualidade subordina indevidamente o direito aos resultados que os juízes podem produzir. O preço desse equívoco é a interrupção do avanço democrático, uma vez que o direito acaba se tornando prioritário sobre a política.

Por tal motivo, tornou-se premente no direito, segundo preconiza Unger (2004a), a reorientação da análise jurídica, para que o direito se transforme em poderoso instrumento de experimentalismo institucional. O propósito da análise jurídica reforjada deve ser solucionar, de maneira ininterrupta, o conflito entre os compromissos programáticos das sociedades e os arranjos institucionais que constrangem a realização plena desses objetivos.

A partir dessas premissas, o presente artigo se presta a duas finalidades.

A primeira é apresentar breve perspectiva de visão do estágio atual da democracia brasileira. Embora não exaustiva, a análise será voltada à demonstração de que (a) constitui problema relevante da democracia brasileira atual a ausência de arenas de dissenso na sociedade civil; (b) diferentemente do que ocorre com outras patologias sociais, como a privatização dos interesses do Estado, a criação de autêntico canal de comunicação entre as instituições e a sociedade civil brasileira depende de efetivos experimentalismos democráticos que não podem ser realizados a partir da jurisdição constitucional ou por exclusivo intermédio dela; e (c) não se tem revelado eficaz no Brasil a política de laissez-faire estatal em relação à promoção social da cidadania.

A segunda finalidade do artigo é explicitar o conceito de democracia que essa proposta de aceleração democrática deve construir no plano teórico, especialmente em razão da dificuldade, mencionada inicialmente, de explicitação do conteúdo de uma agenda de incremento da qualidade dos governos representativos democráticos modernos. 


\section{Esferas públicas políticas como arenas de dissenso moral}

A análise do estágio atual da democracia brasileira realizada por Marcelo Neves, na parte final da obra Entre Têmis e Leviatã: uma relação difícil, representa o ponto de partida do presente artigo. Após qualificar as experiências de 1937-45 e 1965-84 como negações diretas e expressas do Estado de Direito no Brasil, o autor afirmou que os momentos realmente democráticos do país representariam "caso[s] típico[s] de modernidade periférica", nos quais "a crescente complexidade e o desaparecimento do moralismo tradicional não têm sido acompanhados de maneira satisfatória pela diferenciação funcional e pelo surgimento de uma esfera pública fundada institucionalmente na universalização da cidadania" (2008:244).

O retrato de Neves foi primeiramente direcionado ao diagnóstico da ausência de efetiva concretização do Estado de Direito institucionalizado no Brasil. O problema principal apontado pelo autor foi o insuficiente fechamento normativo do subsistema social do direito decorrente da injunção de fatores sociais negativos diversos. O Brasil atual, nesse sentido, foi qualificado como democracia moderna periférica em comparação às democracias europeias. O caminho proposto pelo autor para enfrentamento da questão dispensa experimentalismos institucionais. Resume-se ao abandono de relações de "privatização do Estado que contrapõem-se restritivamente à concretização constitucional dos direitos humanos e da soberania do povo como procedimento" (2008:247).

Por isso, o presente artigo dará preferência ao segundo problema também diagnosticado por Neves: a ausência de esfera pública política, fundada na universalização da cidadania, na sociedade civil brasileira. Será defendido que a política de total ausência estatal em relação à promoção de consciência cívica nos indivíduos não tem funcionado no Brasil atual, ainda que resultados positivos pontuais tenham sido obtidos através da jurisdição constitucional no que diz respeito à maior realização prática dos objetivos programáticos assumidos por ocasião da Constituição Federal de 1988. Será defendido que os resultados dessa política estatal liberal têm sido o distanciamento irresponsável entre representantes e representados e o desaparecimento da política transformativa no país.

Antes, porém, é necessário explicitar o que se entende por esfera pública política. No modelo teórico habermasiano de democracia procedimental, a sociedade civil é apresentada como "espécie de associação que institucionaliza os discursos capazes de solucionar problemas, transformando-os em questões de interesse geral". O significado do termo, para 
Habermas, engloba todos os "movimentos, organizações e associações, os quais captam os ecos dos problemas sociais que ressoam nas esferas privadas, condensam-nos e os transmitem, a seguir, para a esfera pública política"1. Nesse cenário, segundo Habermas, mesmo emitindo sinais e impulsos insuficientes para despertar processos de curto prazo de aprendizagem democrática nos Parlamentos e nas Cortes Constitucionais, a sociedade civil pode efetivamente reorientar o poder oficial através das suas opiniões políticas próprias (2003b:99-106).

A proposta habermasiana de reconhecimento de uma sociedade civil que utiliza linguagem comum "situada abaixo do limiar de diferenciação dos códigos especializados" (2003b:84) foi incorporada no modelo de Estado Democrático de Direito proposto na obra "Entre Têmis e Leviatã: uma relação difícil". Neves, nesse sentido, adotou criticamente a teoria do discurso ao afirmar que, "embora a contribuição habermasiana sobre o mundo da vida e a ação comunicativa não seja imprestável no que concerne à consideração das esferas de comunicação não estruturadas sistemicamente, afigura-se-me imprescindivel a sua releitura à luz da teoria dos sistemas". Para o autor, portanto, o mundo da vida, sobre o qual se ancora a sociedade civil, representa a "base para a construção sistêmica" e, principalmente, o "espaço para a reprodução do dissenso intersubjetivo" (2008:125-126).

A releitura da teoria do discurso proposta por Neves, além de objetivar descarregar a pretensão consensualista do mundo da vida imposta por Habermas, retira corretamente o apoio da prática cotidiana do mundo da vida em inexistentes certezas intuitivamente compartilhadas. Com isso, o conceito habermasiano de esfera pública política como ambiente de reconstrução consensual do mundo da vida dentro de horizontes racionais dá espaço a uma proposta mais modesta: “campo complexo de tensão entre direito e política como sistemas acoplados estruturalmente pela Constituição, de um lado, e mundo da vida e outros subsistemas funcionalmente diferenciados da sociedade" (2008:131).

A esfera pública política surge, assim, como a arena do dissenso. A tarefa de estruturação pluralista, aberta e universal da esfera pública é erigida por Neves ao patamar de “desafio fundamental do Estado Democrático de Direito" (2008:135).

\footnotetext{
${ }^{1} \mathrm{O}$ núcleo da sociedade civil, para Habermas, é necessariamente formado "por associações e organizações livres, não estatais e não econômicas", as quais, mesmo integrantes de "uma esfera pública dominada pelos meios de comunicação de massa e pelas grandes agências, observada pelas instituições encarregadas das pesquisas de opinião e do mercado, $e$ sobrecarregada com o trabalho de publicidade e propaganda dos partidos e organizações políticas", ainda representam o "substrato organizatório do público de pessoas privadas, que buscam interpretações públicas para suas experiências e interesses sociais, exercendo influência sobre a formação institucionalizada da opinião e da vontade" (2003b:99-100).
} 
A partir do detalhamento da releitura das teorias do discurso e dos sistemas proposta por Neves, é fácil perceber que seu diagnóstico a respeito da ausência de arenas de dissenso moral na sociedade civil brasileira traduz a conclusão de que não há: (a) efetivos canais de comunicação entre as opiniões políticas próprias da sociedade brasileira e as decisões tomadas no âmbito do Parlamento e dos Tribunais; (b) efetivas opiniões políticas próprias da sociedade civil brasileira; e (c) real abertura cognitiva dos procedimentos judicial, executivo e legislativo em relação ao mundo da vida e aos anseios das associações não estatais e não econômicas que integram a sociedade civil.

\section{3. $\mathrm{O}$ caso brasileiro}

No que diz respeito à democracia brasileira, Unger visualizou, em texto que escreveu no momento em que se desenrolavam os eventos imediatamente antecedentes à Assembleia Nacional Constituinte de 1987-88, "momento especial de indefinição [que] poderia ser encarado tanto como a voz da oportunidade transformativa, como um sinal da confusão paralisante". Unger, assim, definiu o último período fundacional brasileiro como "exemplo mágico" de momento constitucional em que toda a nação podia distinguir claramente entre o possível e o impossível na política (2004c:67-79).

Para o autor, o peculiar ambiente político prévio à convocação da Assembleia Nacional Constituinte, decorrente do encerramento de "um longo período de uma mal disfarçada ditadura militar", formou o contexto necessário para que, a partir de uma esfera pública política realmente aquecida, o Brasil se tornasse base de testes para todas as opções disponíveis de projetos políticos para a humanidade. Unger, assim, definiu a situação brasileira durante o período constituinte como "momento mágico de união" entre grupos política, econômica e socialmente distintos em favor da criação de algo novo (2004c:67-79).

É possível perceber que Unger encontrou, no último momento constituinte do Brasil, o exemplo ideal da improvável aliança entre a classe pobre estigmatizada, a classe média trabalhadora e os detentores dos meios de produção, criada em decorrência das experiências vivenciadas coletivamente pela sociedade brasileira durante o período do governo militar. Nesse momento "mágico", segundo Unger, o principal objetivo político da sociedade civil brasileira deveria ser a criação de mecanismos institucionais que "garantissem um elevado patamar de militância cívica" no Brasil (2004c:76). 
Sem ingressar no mérito dessa visão política, a leitura que o presente artigo faz da proposta de Unger é a de que os arranjos acima mencionados funcionariam como instrumentos garantidores de solidariedade forçada em substituição à solidariedade espontânea $^{2}$ que certamente cessaria assim que o momento fundacional brasileiro se encerrasse. Não é necessário admitir que a Assembleia Nacional Constituinte de 1987-88 e os seus antecedentes tenham representado especial momento de mobilização democrática brasileira e de efetivo surgimento autônomo de esfera pública política na sociedade civil para reconhecer que, a despeito do inequívoco progresso moral gerado a partir da Constituição Federal de 1988, a quantidade de política transformativa gerada no Brasil tem diminuído nos anos recentes. Essa conclusão, com efeito, independe da escolha pela versão daqueles que defendem que o último período constituinte brasileiro teria representado o meritório resultado do efeito totalmente desorganizador dos projetos das elites detentoras do poder decorrente de amplo e inédito processo de mobilização popular (Barbosa, 2009) ${ }^{3}$ ou dos autores que enxergam o referido momento fundacional como o fruto de mero acordo firmado entre líderes parlamentares (Jobim, 2004) ${ }^{4}$.

\footnotetext{
${ }^{2}$ É necessário explicar, para que seja possível a compreensão mais precisa da mensagem que o artigo procura passar, que a oposição entre os conceitos de solidariedade forçada e solidariedade espontânea diz respeito exclusivamente ao papel do Estado em relação ao desenvolvimento da consciência cívica dos cidadãos. No primeiro caso, há uma política estatal literalmente indutiva, enquanto no segundo a postura pública é liberal. A diferença, portanto, é a presença de uma "agenda de cidadania" (Ackerman, 2012) por parte do Estado.

${ }^{3} \mathrm{O}$ seguinte exemplo da maciça participação popular no último processo constituinte brasileiro é dado por Leonardo Barbosa: "Os organizadores do relatório 'Cidadão constituinte: a saga das emendas populares' consideraram a possibilidade de apresentação de emendas desse tipo como 'a primeira mudança no quadro político institucional brasileiro obtida pelo longo esforço que vinha sendo desenvolvido, desde o início de 1985, pelos plenários, comitês e movimentos pró-participação popular na Constituinte'(MICHILES, 1989, p. 54). A proposição de emendas consistia em mecanismo mais avançado que a participação em audiências ou oferecimento de sugestões e correspondia a um avanço qualitativo da Constituinte em termos de abertura à sociedade (1989, p. 55). Enquanto as sugestões encaminhadas às Comissões e Subcomissões temáticas constituíam apenas subsídios aos trabalhos dos constituintes, as emendas que contassem com pelo menos trinta mil assinaturas de eleitores e apoio de, no mínimo, três entidades associativas legalmente constituídas integravam o processo de elaboração da nova Constituição, e só poderiam ser excluídas dele pela manifestação unânime da Comissão de Sistematização. (...) No total foram apresentadas 122 emendas populares, reunindo mais de doze milhões de assinaturas. Considerando as regras regimentais para a apresentação das propostas das emendas (que permitiam ao cidadão assinar no máximo três propostas), a lógica da coleta das assinaturas (que mesclava campanhas solicitando a assinatura em três propostas com outras que preferiam priorizar apenas uma iniciativa) e o universo do colégio eleitoral de 1987 (então com praticamente setenta milhões de eleitores), estima-se que entre dez e doze por cento dos cidadãos brasileiros participaram diretamente do processo constituinte (MICHILES, 1989, p. 104-105). Igualmente impressionante é o número de entidades envolvidas na coleta das assinaturas: quase trezentas entidades dos mais diferentes perfis foram mobilizadas. As entidades sindicais, profissionais e técnicocientíficas responderam por $42 \%$ desse total, com destaque também para as entidades civis (30\%) e religiosas (9\%)" (2009: 201-202).

${ }^{4}$ Segundo Nelson Jobim, em depoimento à Comissão Especial destinada a proferir parecer sobre a Proposta de Emenda Constitucional n. 157/2003, na audiência pública n. 100/2006, "todas as Constituições brasileiras foram sempre processos de transição, ou seja, não tivemos rompimentos na história brasileira. quando o regime anterior se esboroava, logo a seguir apresentava-se uma solução à situação anterior. Portanto, é difícil, na história política brasileira, utilizarse de instrumento ou de linguagem importadas de outros países, como, por exemplo, os conceitos de Constituinte originário e Constituinte derivado".
} 
É suficiente apenas constatar que, ainda que o referido momento eventualmente tenha representado situação especial de solidariedade espontânea que uniu a população brasileira, o arrefecimento do engajamento cívico não demorou a ocorrer ${ }^{5}$. Para tanto, bastou que cessassem as circunstâncias político-econômicas que tornavam literalmente imperioso o interesse cívico da população brasileira.

A peculiaridade democrática do Brasil recente é que a diminuição da participação social na política, decorrente do desaparecimento do último momento constitucional brasileiro, não gerou diminuição na quantidade de política constitucional realizada no país. $\mathrm{O}$ melhor exemplo disso é o fato de que, no curto período de tempo que se passou desde a promulgação da Constituição Federal de 1988, foram efetuadas setenta e uma emendas constitucionais. A peculiaridade brasileira é a irrelevância democrática do conteúdo da significativa maioria dessas emendas, notadamente as mais recentes ${ }^{6}$.

Inicialmente, todavia, é mais do que forçoso reconhecer que a Constituição Federal de 1988 teve o mérito de apresentar os fundamentos que permitiram ao Brasil obter a confiança democrática necessária para integrar-se definitivamente à ordem global, atingindo inquestionável progresso econômico e social.

Não é possível, ainda assim, atribuir exclusivamente ao próprio texto constitucional brasileiro os méritos dessa conquista. Conforme reconhecido por Fernando Henrique Cardoso, foi necessário que os sucessivos governos eleitos a partir de 1989 experimentassem institucionalmente alternativas que permitissem ao país superar o principal defeito do texto constitucional: o fato de "seu vigor democrático, capaz de desenhar um futuro socialdemocrático nas áreas da previdência, da saúde, da reforma agrária e da educação" não ter sido acompanhado pelas "condições institucionais propícias para gerar a riqueza necessária ao custeio de tão altos propósitos" (2010:176)7. A Constituição Federal de 1988, nesse

\footnotetext{
${ }^{5}$ Essa conclusão independe de investigação mais detalhada a respeito de quem eram os detentores das rédeas reais de condução do processo constituinte brasileiro. A esse respeito, ainda que seja relevante investigar (a) a dimensão da efetiva influência social nos trabalhos dos parlamentares constituintes, e (b) o real peso dos trabalhos desempenhados pela Comissão Afonso Arinos no que diz respeito à formatação do texto da Constituição de 1988, não há como não se reconhecer que a população apoiou a convocação da Assembleia Nacional Constituinte e referendou tacitamente o resultado final dos seus trabalhos.

${ }^{6}$ Merecem destaque, a esse respeito, as seguintes emendas constitucionais: (a) EC n. 61/2009, que alterou os parâmetros de idade para ingresso no Conselho Nacional de Justiça; (b) EC n. 50/2006, que alterou o artigo 57 da Constituição Federal para modificar as datas das reuniões do Congresso Nacional e modificou os critérios para convocação extraordinária; e (c) EC n. 69/2012, que transferiu da União para o Distrito Federal as atribuições para organização e manutenção da Defensoria Pública do Distrito Federal.

${ }^{7}$ Segundo Fernando Henrique Cardoso, a Constituição Federal de 1988 “manteve o viés, que se justificava nas décadas anteriores, de um controle estatal forte da produção, de inibição ao capital externo e uma estrutura tributária que ou deixaria o Estado à míngua ou as empresas e a população à morte" (2010:176). Para o autor, "extensa e detalhista ao extremo, a Constituição de 1988 era - em larga medida ainda é - uma peça contraditória. Avançada no reconhecimento
} 
sentido, apenas esboçou o plano do Estado Social, sem indicar, contudo, suas fontes de financiamento.

De maneira apenas aparentemente paradoxal, o que propiciou o surgimento das condições políticas necessárias para o desenvolvimento dos necessários rearranjos institucionais profundos no Brasil pós-constituinte foi o respeito ao rito constitucional que marcou tanto o impeachment do Presidente Fernando Collor de Mello como sua substituição pelo Vice-presidente Itamar Franco ${ }^{8}$. Foi exatamente a obediência às previsões constitucionais no momento da mudança presidencial que revigorou a confiança social no processo democrático brasileiro e permitiu a criação de coalização partidária ampla para a realização de reformas necessárias ao enfrentamento dos graves problemas econômicos que marcavam o Brasil no início da década de $1990^{9}$.

Profundas alterações institucionais foram conduzidas pelo Congresso Nacional, consubstanciadas em emendas constitucionais voltadas à alteração do serviço público, da previdência social, dos monopólios estatais e da definição do conceito de empresa nacional. Além disso, no âmbito empresarial, (a) foi criado, em fevereiro de 1995, novo regime legal para a concessão e permissão da prestação de serviços públicos; e (b) foram inventadas as agências reguladoras. No campo fiscal, foi aprovada, em maio de 2000, a Lei de

dos direitos e garantias fundamentais do cidadão, generosa na antevisão dos direitos sociais, nela também se entrincheiraram interesses especiais ligados às estruturas do Estado varguista, além do patrimônio arraigado na cultura política brasileira" (2010:148-149).

${ }^{8}$ Outra consequência favorável à criação de política transformativa decorrente do impeachment do Presidente Fernando Collor foi a seguinte: a "passagem meteórica [de Fernando Collor] sacudiu o mundo político e ampliou o espaço na mídia para discussão sobre reformas. Ao levar o paroxismo a intervenção presidencial na cena política e na vida econômica, é possível que ele tenha deixado na sociedade a demanda por uma liderança que, sem retroceder à visão do passado, pudesse restabelecer a confiança numa agenda não traumática de mudanças. Quando o agravamento da crise depois do impeachment bateu no limite da tolerância da sociedade à superinflação e baixou as resistências à mudança no Congresso, havia uma alternativa suficientemente amadurecida para se oferecer ao país" (2010:148-149).

${ }^{9}$ A esse respeito, Fernando Henrique Cardoso apresenta verdadeiro testemunho pessoal das dificuldades enfrentadas à época em que assumiu o Ministério da Fazenda no governo do Presidente Itamar Franco: "Em maio de 1993, quando assumi o Ministério da Fazenda, três ministros haviam me antecedido em apenas sete meses e a inflação chegava aos $30 \%$ ao mês. Como se isso não bastasse, a tensão política estava de volta, agora com foco no Congresso, às voltas com um escândalo de corrupção na distribuição de recursos orçamentários que levaria à cassação de vários deputados, incluindo alguns de grande projeção. Compreende-se, nessas condições, que o propósito de atacar de frente os 'três grandes problemas do país: a inflação, a inflação e a inflação', como enfatizei em meu discurso de posse como ministro, tenha sido recebido com ceticismo, apesar da boa vontade da mídia, dos empresários, da maioria do Congresso e do público em geral. Com um presidente legalmente investido mas sem respaldo direto nas urnas (no Brasil, como nos Estados Unidos, o candidato a vice-presidente não é votado) e o Congresso mergulhado numa penosa autodepuração, não se acreditava que houvesse condições políticas para dar essa batalha. Nem tempo para vencê-la, já que haveria eleições gerais no fim de 1994 e a eleição presidencial seria antecipada para a mesma data por uma emenda constitucional. Restava pouco mais de um ano antes de a campanha eleitoral reter os congressistas em suas bases, impossibilitando a aprovação de qualquer medida legislativa complexa, que exigisse a presença de maioria em plenário. Contudo, mesmo no prazo apertado deixado pelo calendário eleitoral, foi possível reunir uma equipe técnica competente no Ministério da Fazenda - requisito vital para um Ministro que não era economista - formular uma estratégia inovadora de estabilização, combinando medidas ortodoxas e heterodoxas, e conseguir apoio político para implementála - no que a experiência anterior do ministro como congressista mostrou-se valiosa. O êxito do Plano Real e o ciclo de mudanças por ele inaugurado pareceram desmentir ou pelo menos relativizar os diagnósticos que enfatizavam os obstáculos políticos para a estabilização da economia e a realização de reformas" (2010:144-145). 
Responsabilidade Fiscal, com critérios cogentes para endividamento nos três níveis de governo. Nas esferas social, da saúde e da educação, também por emendas constitucionais, foram redesenhadas as formas de participação dos entes federativos no financiamento do ensino fundamental e da saúde, bem como inventado o Fundo de Combate à Pobreza. No próprio domínio da jurisdição constitucional, por intermédio das Leis n. 9.868/98 e 9.882/98, foi reinventado por completo o método de atuação do Supremo Tribunal Federal.

Nesse período, a Constituição Federal foi literalmente reinventada institucionalmente através de trinta e cinco emendas e mais de quinhentas leis complementares, leis ordinárias e medidas provisórias com conteúdo relevante (Cardoso, 2010:152-153). A peculiaridade desse período democrático do Brasil é que o experimentalismo institucional profundo ocorreu dentro das regras constitucionais procedimentais em vigor e mediante deliberações legislativas.

O resultado do experimentalismo institucional brasileiro realizado em conformidade com as regras democráticas ${ }^{10}$, com segurança, foi a criação de condições sólidas para que o país obtivesse o expressivo progresso econômico vivenciado na última década ${ }^{11}$.

Ainda assim, a despeito das notáveis conquistas obtidas mais recentemente em termos de inclusão social, o ritmo das reformas institucionais diminuiu drasticamente a partir do momento em que o Brasil alcançou estabilidade econômica. Há duas maneiras de se analisar esse fenômeno. A primeira sugere que, por tentativa e erro, o Brasil alcançou seu ponto ótimo institucional através da reinvenção constitucional desenhada na década de 1990, de modo que, a partir de então, bastaria ao país se esforçar para concretizar seus compromissos programáticos segundo os critérios e arranjos então existentes. A política extraordinária seria relegada, então, a outro distante mágico momento especial de crise e a política transformativa seria substituída pela política ordinária. A mensagem implícita é a de

\footnotetext{
${ }^{10}$ Deve ser mencionada, como exceção relevante à regra de ausência de alteração na disciplina de funcionamento do poder político no Brasil da época, a Emenda Constitucional n. 16/1997, que permitiu a reeleição do Presidente da República, dos Governadores dos Estados e do Distrito Federal e dos Prefeitos.

${ }^{11} \mathrm{O}$ testemunho de Fernando Henrique Cardoso a respeito dessa questão é bastante esclarecedor: "Nem todas as reformas foram completadas em toda a extensão proposta. Não serei eu o melhor juiz de seu acerto, nem posso garantir que tenham alcançado o ponto de não retorno. Parece-me inegável, de todo modo, que elas avançaram o bastante para sustentar a estabilidade da economia nos últimos dez anos. E, se não assentaram sobre alicerces inabaláveis um novo modelo de desenvolvimento, pelo menos redefiniram os seus contornos. (...) Em nenhum outro país da América Latina, que eu saiba, as reformas envolveram um esforço parecido de reconstrução de consenso no Legislativo. No Chile, as reformas de Pinochet dispensaram a chancela do Congresso. Na Argentina, a privatização, a desregulamentação e o que houve de enxugamento da máquina estatal foram feitos em grande parte por delegação legislativa ao Executivo. Em retrospecto, talvez isso tenha sido vantajoso para o Brasil. O atalho argentino para as reformas, ao que parece, deu em instituições mais débeis e não mais fortes. O tortuoso caminho brasileiro levou-nos a uma situação mais sólida desse ponto de vista. Toda a pauta legislativa mencionada acima tramitou dentro de um quadro político-institucional bastante inalterado, com os mesmos atores e as mesmas regras do jogo, ou quase as mesmas, que se supunha colocar obstáculos praticamente intransponíveis para as reformas" (2010:152-153).
} 
que seria perigoso alterar a dinâmica dos arranjos desenvolvida anteriormente, seja pela perfeição do desenho institucional vigente, ou pela inaptidão dos agentes políticos atuais de propor bons experimentos.

A segunda visão, adotada no presente artigo, recomenda que se substitua a política ordinária pela política transformativa, com contínua e incessante preocupação com a redefinição dos mecanismos institucionais brasileiros para que, independentemente do aparecimento de crises, haja incremento na realização prática dos compromissos programáticos assumidos por ocasião da Constituição Federal de 1988.

O caminho apartidário sugerido não é a perpetuação ordinária do momento constituinte, o que levaria a inaceitável modelo niilista de busca pela impossível transcendência ao contexto. A proposta é mais apenas retomar o experimentalismo institucional segundo as regras do jogo, prática que marcou o país após o impeachment do Presidente Fernando Collor de Mello. O objetivo, portanto, é apenas a recuperação da agenda política pelos agentes políticos, em substituição à agenda política conduzida pelo jurista, o que se tornou regra recentemente no Brasil.

A esse respeito, ainda que existam bons exemplos de avanços institucionais recentes no Brasil obtidos por meio do Poder Executivo e Legislativo, como é o caso das cotas raciais sociais nas universidades públicas ${ }^{12}$, bem como das leis da Ficha Limpa e de Acesso à Informação, é inquestionável que a qualidade da política praticada pelos agentes políticos caiu de forma drástica nos anos mais recentes. Os mais relevantes exemplos de política transformativa praticados nos últimos anos no país:

(a) ocorreram a partir da jurisdição constitucional, como a regulamentação da união homoafetiva (ADI n. 4277 e ADPF n. 132), a autorização da realização de aborto de fetos anencefálicos (ADPF n. 54) e a permissão da realização da chamada "marcha da maconha" (ADPF n. 187); ou

(b) somente ganharam força após o referendo do Supremo Tribunal Federal, como foi o caso das cotas das universidades - com o surgimento da Lei Federal n.

\footnotetext{
${ }^{12}$ A esse respeito, o presente artigo comunga integralmente da visão do Ministro Gilmar Ferreira Mendes, do Supremo Tribunal Federal, manifesta em voto proferido no julgamento da ADPF n. 186/DF e da ADI n. 3.330-1/DF, no sentido de que (a) a instituição de cotas raciais para ingresso dos interessados em cursar os cursos de graduação da Universidade de Brasília e (b) a instituição do Programa Universidade para Todos, através de Medida Provisória n. 213/2004, posteriormente convertida na Lei n. 11.096/05, representaram notáveis exemplos de experimentalismo institucional. O capítulo 07 do voto proferido pelo Ministro Gilmar Ferreira Mendes no julgamento da ADI n. 3.330-1/DF, intitulado "Uma palavra sobre experimentalismo institucional", é bastante claro quanto a essa questão.
} 
12.711/2012 e do "Programa de Inclusão com Mérito no Ensino Superior Público Paulista" - e das próprias Lei da Ficha Limpa e de Acesso à Informação.

O melhor retrato recente da dormência cívica que domina o Brasil atual e da pequena relevância atual do Poder Legislativo no cenário político veio do caso da regulamentação do Fundo de Participação dos Estados. Como é sabido, em 24 de fevereiro de 2010, ao julgar as ADIs n. 875/DF, 1.987/DF, 2.727/DF e 3.243/MT, o Supremo Tribunal Federal declarou a inconstitucionalidade, sem a pronúncia da nulidade, do artigo $2^{\circ}$, incisos I e II, $\S 1^{\circ}, 2^{\circ}$ e $3^{\circ}$, bem como do Anexo Único, da Lei Complementar n. 62/1989, assegurando a aplicação dos referidos textos até 31 de dezembro de 2012.

$\mathrm{O}$ argumento fundamental do julgamento foi o fato de que o Poder Legislativo não havia cumprido adequadamente seu dever constitucional de legislar quando criou políticas de divisão de receita que desrespeitavam a diretriz prevista no artigo 161 da Constituição Federal de promoção de equilíbrio socioeconômico entre os Estados da Federação. Segundo entendimento do Supremo Tribunal Federal, a legislação que então regulamentava o Fundo de Participação dos Estados decorria exclusivamente de acordos políticos e não considerava critérios objetivos e variáveis, como população e produto interno bruto dos municípios.

Durante o extenso prazo estabelecido pelo Supremo Tribunal Federal para que a norma inconstitucional vigorasse, não foi possível alcançar, no âmbito do Congresso Nacional, consenso relacionado à criação de nova forma de rateio do fundo constitucional ${ }^{13}$. Encerrado o prazo de vigência da norma declarada inconstitucional, o resultado foi um constrangedor manifesto subscrito por membros do Senado, intitulado "Uma nova presidência e um novo rumo para o Senado" ${ }^{14}$. O documento destaca a percepção de parte relevante dos integrantes do Senado de que "nos últimos anos o Parlamento tem sido um poder menor" na democracia brasileira.

Três fatores principais são apontados para fundamentar esse diagnóstico: (a) a submissão do Parlamento às medidas provisórias, que estariam sendo utilizadas "em assuntos sem emergência" e aprovadas "sem debate e em prazos vergonhosamente curtos"; (b) a “judicialização da política, com a clara intervenção da Justiça, impondo legislações e contestando decisões tomadas no Parlamento, muitas vezes respondendo a iniciativas dos

\footnotetext{
${ }^{13}$ É necessário reconhecer que houve manifestações por parte do Congresso Nacional no sentido de promover a realização de discussões relacionadas à criação de novo normativo que disciplinasse o assunto. A principal delas foi a tardia criação, pelo então Presidente do Senado Federal José Sarney, de uma comissão destinada a estudar o assunto e a propor possíveis soluções para os principais problemas federativos atualmente existentes no Brasil.

${ }^{14}$ Disponível em http://www.cristovam.org.br/portal3/index.php?option=com_content\&view=article\&id=5211:manifesto-desenadores-por-uma-nova-presidencia-e-um-novo-rumo-para-o-senado\&catid=170:super-manchete\&Itemid=100003.
} 
próprios parlamentares descontentes com o resultado das votações"; e (c) o comportamento ineficiente dos próprios integrantes das Casas Legislativas.

Com relação à dormência política dos membros do Congresso Nacional, os seguintes recentes exemplos foram apresentados no manifesto em questão: (a) a existência de 3.060 vetos presidenciais sem análise ao longo de quase duas décadas ${ }^{15}$; (b) a "ridícula tentativa de organizar a votação de todos esses vetos em uma tarde, como forma de passar por cima de decisão do Supremo" Tribunal Federal; (c) o encerramento das atividades legislativas do ano de 2012 sem a votação do orçamento para o ano fiscal de 2013; (d) o "fim melancólico da CPMI [do Cachoeira], com um relatório de duas laudas e nenhum indiciamento"; (e) "o constrangimento de que a Administração do Senado passou anos cometendo o equívoco de não descontar Imposto de Renda de parte do salário dos senadores e, ao ser surpreendida pela Receita Federal, decidiu pagar com recursos públicos, o que era dívida pessoal de cada senador, embora provocada por erro da Administração da Casa"; (f) os "plenários vazios,

\footnotetext{
${ }^{15}$ A questão da ausência de deliberação do Congresso Nacional acerca de 3.060 vetos presidenciais foi utilizada como argumento pelo Ministro Luiz Fux, do Supremo Tribunal Federal, para deferir questionável medida liminar nos autos do mandado de segurança n. 31.816/DF. O conteúdo da ementa da referida decisão monocrática foi o seguinte: "DIREITO CONSTITUCIONAL. DEVIDO PROCESSO LEGISLATIVO. CONTROLE JUDICIAL. CABIMENTO. LEGITIMIDADE ATIVA AD CAUSAM EXCLUSIVA DO PARLAMENTAR EM EXERCÍCIO. MANDADO DE SEGURANÇA CONHECIDO. LIMITES CONSTITUCIONAIS AO PODER DE DELIBERAÇÃO LEGISLATIVA ACERCA DO VETO PRESIDENCIAL. ART. 66, §§ $4^{\circ}$ E $6^{\circ}$, DA CF/88. SOBRESTAMENTO DAS DEMAIS PROPOSIÇÕES ATÉ A DELIBERAÇÃO DO VETO PENDENTE. POSSIBILIDADE. EXISTÊNCIA DE MAIS DE 3.000 VETOS AINDA NÃO APRECIADOS. INERTIA DELIBERANDI CONFIGURADORA DE OMISSÃO INCONSTITUCIONAL. NECESSIDADE DE OBSERVÂNCIA DA ORDEM CRONOLÓGICA DE COMUNICAÇÃO DOS VETOS PARA FINS DE DELIBERAÇÃO. OFENSA AO PODER DE AGENDA POLÍTICA DO LEGISLATIVO NÃO CONFIGURADA. REVISITAÇÃO DA JURISPRUDÊNCIA SOBRE QUESTÕES INTERNA CORPORIS. ESTADO DE DIREITO E PROTEÇÃO CONSTITUCIONAL DAS MINORIAS. ALEGAÇÃO DE VIOLAÇÃO A NORMAS REGIMENTAIS. CONHECIMENTO. DELIBERAÇÃO ACERCA DE MATÉRIA NÃO CONSTANTE DA ORDEM DO DIA. OFENSA À PREVISIBILIDADE E À CONFIANÇA RECÍPROCA NO FUNCIONAMENTO PARLAMENTAR. AUSÊNCIA DE RELATÓRIO PRÉVIO DE COMISSÃO MISTA. OFENSA AOS ARTS. 104 E 105 DO REGIMENTO COMUM DO CONGRESSO NACIONAL. FUMUS BONI IURIS E PERICULUM IN MORA CONFIGURADOS. LIMINAR DEFERIDA.

1. O parlamentar no pleno exercício do mandato eletivo ostenta legitimidade ativa ad causam para impetrar mandado de segurança com a finalidade de prevenir atos no processo de aprovação de leis e emendas constitucionais que não se compatibilizem com o processo legislativo constitucional. Precedentes do STF: MS $n^{o}$ 20.257, rel. Min. Moreira Alves, Tribunal Pleno, j. 08/10/1980, DJ de 27.02.1981; MS n 21.642, rel. Min. Celso de Mello, RDA 191/200; MS n ${ }^{\circ} 21.303$, Min. Octavio Galloti; MS n $n^{\circ}$ 24.356, rel. Min. Carlos Velloso, Tribunal Pleno, j. 13/02/2003, DJ 12.09.2003; e MS no 24.642, rel. Min.Carlos Velloso, Tribunal Pleno, j. 18/02/2004, DJ 18.06.2004. 2. O veto aposto pelo Presidente da República, na dinâmica da sua rejeição pelo Poder Legislativo, se sujeita aos limites jurídicos delineados no art. 66, $\$ \S 4^{\circ}$ e $6^{\circ}$, da Constituição Federal; vale dizer, a deliberação legislativa acerca do agir presidencial deve ser imediata, competindo ao Poder Judiciário a sindicabilidade do comando constitucional acaso violado. 3. É inconstitucional a deliberação aleatória dos vetos presidenciais pendentes de análise legislativa, cuja simples existência subtrai do Poder Legislativo a autonomia para definição da respectiva pauta política, ex vi do $66, \$ 6^{\circ}$, da CF/88. 4. É que resta necessária a deliberação dos vetos presidenciais na sua ordem cronológica de comunicação ao Congresso Nacional, o que importa na apreciação do veto parcial $n^{o} 38 / 2012$, aposto pela Presidente da República ao Projeto de Lei $n^{o}$ 2.565/2011, somente após a análise de todos aqueles cujo prazo constitucional de apreciação já tenha expirado. 5. São cognoscíveis em sede mandamental as alegações de ofensa à disciplina das regras dos regimentos das Casas Legislativas, sendo certo que pela sua qualidade de normas jurídicas reclamam instrumentos jurisdicionais idôneos a resguardar-lhes a efetividade. Rejeição da doutrina das questões interna corporis ante sua manifesta contrariedade ao Estado de Direito (art. $1^{o}$, caput, CF/88) e à proteção das minorias parlamentares. 6. A leitura do veto parcial $n^{\circ} 38 / 2012$, em regime de urgência, na sessão legislativa de 12.12.2012, violou as disposições regimentais que impedem (a) a discussão de matéria estranha à ordem do dia e (b) a deliberação do veto sem prévio relatório da comissão mista. 7. Fumus boni iuris e periculum in mora configurados. Medida liminar deferida."
} 
Comissões, o voto com o corpo (...) sem o compromisso de pronunciamento ou com a cobertura do voto secreto"; (g) a existência de simulacro de eleição para a presidência do Senado Federal no biênio 2013-2014 ${ }^{16}$; e, por fim, (h) "depois de três anos de prazo dado pelo Supremo, [a ausência de definição] (...) do funcionamento do Fundo de Participação dos Estados, jogando as finanças dos Estados em um abismo" ${ }^{17}$.

Especificamente com relação ao caso do Fundo de Participação dos Estados, após manobra técnica do Tribunal de Contas da União que permitiu que alguns pagamentos fossem realizados no início do ano de 2013 à míngua de autorização legal específica ${ }^{18}$, o assunto foi embaraçosamente devolvido à apreciação do Supremo Tribunal Federal, por intermédio da ADO n. 23, proposta pelos Estados da Bahia, do Maranhão, de Minas Gerais e de Pernambuco $^{19}$. Em decisão monocrática proferida poucos dias depois, o Ministro Ricardo Lewandowski, exercendo interinamente a presidência do Supremo Tribunal Federal, deferiu parcialmente o pedido formulado pelos autores, permitindo que o repasse das verbas do

\footnotetext{
${ }^{16} \mathrm{O}$ texto do manifesto é bastante duro com relação a esse ponto: "Tudo isso exige que a eleição de um novo presidente seja feita com debates entre nós senadores para, antes da eleição sabermos quais as propostas do novo presidente para recuperar a eficiência e a credibilidade do Senado, ajudando a recuperar a de todo o Parlamento. Mas não é isso que se vê. Ao contrário, saímos para o recesso, cada um em seu Estado, sem saber quais seriam os candidatos (diferentemente dos Deputados que há meses estão no processo eleitoral para escolha de seu próximo presidente). Voltaremos apenas para ratificar o nome, nomeado sem apresentar qualquer proposta que mude o nosso funcionamento. Votaremos como os eleitores que iam às urnas na Primeira República, levando a cédula sem conhecer o nome do candidato escrito nela pelos antigos Coronéis de Interior. Diante disto, o mínimo que nós, como eleitores, podemos fazer é apresentar sugestões para serem ${ }_{17}$ debatidas e, se aprovadas, postas em prática no Senado, sob a coordenação do novo presidente".

O documento também apresenta críticas fortes com relação à ausência de definição, pelo Congresso Nacional, das regras de funcionamento do Fundo de Participação dos Estados dentro do prazo fixado pelo Supremo Tribunal Federal no julgamento das ADIs n. 875/DF, 1.987/DF, 2.727/DF e 3.243/MT: "Este fato se reveste da maior gravidade quando lembramos a essência da existência de um Senado em nossa República, ou seja, mostramos falta de zelo com o federalismo cooperativo inscrito na Carta Magna e penalizamos as unidades federadas mais frágeis, contribuindo para a permanência de enormes desigualdades territoriais".

Decisão Normativa n. 123/2012, segundo a qual: "Diante desse quadro de indefinição e considerando que o parágrafo único do art. 616 da Constituição Federal atribui ao TCU a responsabilidade pelo cálculo das quotas referentes aos fundos de participação, e mais, considerando, ainda, a exigência contida no art. 92 da Lei 5.172, de 25 de outubro de 1966 (Código Tributário Nacional), no sentido de esta Corte de Contas encaminhar os coeficientes ao Banco do Brasil até o último dia útil de cada exercício, determinei à Secretaria de Macroavaliação Governamental a imediata realização do cálculo dos coeficientes de FPE. (...) Ao ordenar a instrução definitiva do feito, ponderei o fato de a União não poder reter os aludidos recursos, os quais pertencem constitucionalmente aos Estados e ao Distrito Federal e pautei-me, sobretudo, nos princípios da segurança jurídica e da prudência por entender que os dispositivos da LC 62/1989 questionados pelo STF ainda estarão em vigor até 31/12/2012. Dessa forma, até que sobrevenha nova disciplina legal, devem ser mantidos os coeficientes para o exercício de 2013 com base no Anexo Único da LC 62/1989." 19

O pedido formulado pelos autores da ADO foi o seguinte: "Desse modo, considerando-se que o artigo $12-F$, $\$ 1^{o}$, da Lei $n$. 9.868/99 confere a essa Suprema Corte competência para determinar qualquer providência que se revele necessária para assegurar a efetividade das decisões cautelares que profira em sede de ação direta por omissão, afigura-se devida a fixação de novo prazo para a atuação dos órgãos legislativos competentes, prorrogando-se, durante esse período, a vigência das normas declaradas inconstitucionais no julgamento das referidas ações diretas".
} 
Fundo de Participação dos Estados continuasse sendo realizada conforme as regras da Lei Complementar n. 62/1989, pelo prazo adicional de cento e cinquenta dias ${ }^{20}$.

Mesmo assim, é forçoso concluir que a total passividade do Congresso Nacional em relação a esse tema sensível, que interfere drasticamente no equilíbrio federativo do país, representa claro exemplo de que existe pouco espaço para a realização de política transformativa no Brasil atual, em contraste ao período de intensa atividade criativa que marcou as Casas Legislativas nos anos seguintes ao impeachment do Presidente Fernando Collor de Mello. O texto do manifesto mencionado anteriormente elenca diversos fatos que podem sustentar essa conclusão. O mais relevante deles, com segurança, é a percepção de que o importante desenvolvimento econômico recente do Brasil gerou certa acomodação social e a percepção política de que a inovação institucional não é mais necessária no país. O fetichismo institucional, portanto, dominou a percepção política na democracia brasileira atual.

Nesse cenário, é fundamental perceber a literal impossibilidade de que a jurisdição constitucional sozinha coloque combustível na agenda parlamentar de debates, seja por meio de técnicas de decisão que efetivamente gerem um diálogo institucional apto a permitir a superação de entraves políticos, ou por intermédio da efetiva influência dos posicionamentos do Supremo Tribunal Federal na dormência democrática brasileira recente.

De fato, ultrapassados o momento fundacional de política extraordinária que marcou a inauguração de uma nova ordem constituinte e o período de graves crises econômicas que manteve o interesse social pela política transformativa no início da década de $1990^{21}$, tornouse necessária a criação de instrumento distinto da jurisdição constitucional para o surgimento de solidariedade forçada no âmbito da sociedade civil brasileira.

\footnotetext{
${ }^{20}$ Em manifestação apresentada anteriormente à apreciação do pedido liminar, o Con gresso Nacional se defendeu no seguinte sentido: "Contudo, não há omissão inconstitucional do Congresso Nacional como apontam os Requerentes, já que têm curso regular nas Casas Legislativas Projetos de Lei Complementar destinados a disciplinar a forma de distribuição dos recursos do FPE, não havendo, portanto, inércia do Poder Legislativo, a justificar qualquer intervenção do Poder Judiciário em suas atividades típicas, em atenção ao princípio da separação dos poderes. A realidade fática demonstrou que o prazo de manutenção da vigência da norma (até 31/12/2012), fixado pelo STF, foi exíguo para debate, aprovação, vigência e eficácia de uma nova Lei Complementar que substituísse os critérios adotados desde 1989, ante as inúmeras atividades desenvolvidas pelo Congresso Nacional nos últimos dois anos, associada ao fato de que em 2010 ocorreram eleições federais, conforme expressamente mencionado no acórdão do STF." 21

É curioso notar, nesse cenário de profundas alterações institucionais que marcou o Brasil desde os eventos que antecederam a Assembleia Nacional Constituinte de 1987-88, especialmente a campanha pelas diretas-já em 1984, até mais recentemente, o relevante peso atribuído por Fernando Henrique Cardoso ao papel da opinião pública: "O Brasil é um país com proporcionalmente poucos eleitores mas com uma quantidade de telespectadores e radiouvintes que cobre praticamente a totalidade da população. A oferta de informação pelos dois veículos, rádio e televisão, é razoavelmente pluralista e independente. A força política das massas informadas pela mídia eletrônica se fez sentir pela primeira vez na campanha por 'eleições diretas-já' em 1984, que marcou o ocaso do regime militar. Todos os acontecimentos políticos importantes desde então trazem a sua marca, da eleição indireta de Tancredo Neves ao impeachment de Collor, do Plano Cruzado ao Real, passando pelas eleições periódicas. A presença desse ator difuso altera profundamente as formas de exercício democrático do poder. Não basta ser votado, ainda que por dezenas de milhares, nem estar revestido de autoridade legal. A legitimação das decisões requer o esforço incessante de explicar suas razões e convencer a opinião pública" (2010:160-161).
} 


\section{Da solidariedade espontânea para a solidariedade forçada: superação da política de laissez-faire estatal quanto à cidadania democrática}

No item anterior, foi visto que, segundo Unger, a Assembleia Nacional Constituinte de 1987-88 representou o encerramento do último momento brasileiro de solidariedade espontânea. Para o autor, o ambiente sócio-político que circundou a convocação da Assembleia Nacional Constituinte de 1987-88 gerou verdadeiro momento constitucional mágico de união entre grupos política, econômica e socialmente distintos no Brasil. De maneira implícita, Unger identificou, nesse momento brasileiro, a improvável solidariedade espontânea, necessária para o aquecimento democrático.

O problema da solidariedade espontânea é que ela desaparece no exato momento em que o ambiente de mobilização popular que marca os momentos constitucionais perde sua razão motivadora ou alcança, total ou parcialmente, o seu objetivo. A dificuldade, quando se esvai a solidariedade espontânea, é justamente imaginar mecanismos para que ocorra o surgimento da solidariedade forçada.

No caso brasileiro, como visto, o interesse da população pela política apenas se manteve aceso após o encerramento da Assembleia Nacional Constituinte de 1987-88 em decorrência (a) do significado democrático que representou o impeachment do Presidente Fernando Collor de Mello e (b) do profundo incômodo social causado pela crise econômica que atingiu o Brasil ainda no início da década de $1990^{22}$. Nesse sentido, a arena do dissenso formada na sociedade civil brasileira - entendida como a opinião pública com as suas atenções realmente voltadas à política - somente se dissipou com a estabilização econômica ${ }^{23}$. O último momento constitucional brasileiro, assim, prolongou-se para além do período

\footnotetext{
22 A esse respeito, vale mencionar novamente o testemunho de Fernando Henrique Cardoso: “Ao enfraquecimento momentâneo das forças políticas tradicionais somava-se outro fator decisivo: a saturação da sociedade depois de anos de convivência com os efeitos desagregadores da superinflação. Com preços subindo quase todo dia e acumulando aumentos médios acima de $20 \%$ ao mês, praticamente não havia setores e camadas imunes. Todos eram de algum modo impactados: os assalariados, aposentados e pensionistas, pela corrosão acelerada do poder de compra de seus rendimentos fixos; os trabalhadores por conta própria e microempresários sem acesso ao sistema bancário, pela desvalorização de seus escassos ativos em dinheiro; a alta classe média e os empresários, pelas imensas dificuldades de planejar e investir no ambiente superinflacionário, mesmo tendo acesso a aplicações financeiras indexadas. Qualquer proposta crível de ataque à inflação tenderia a obter, nessas circunstâncias, consenso amplo na sociedade, deixando em segundo plano outros interesses eventualmente divergentes e até conflitantes. Consenso que, uma vez repercutido pelos meios de comunicação de massa, terminaria por influenciar os que tomavam decisões no governo e no Congresso. Nossos esforços para 'vender' o Plano Real voltaram-se, por isso, tanto para dentro do governo e do Congresso quanto para fora do sistema político, para o convencimento da sociedade. A ambas tarefas me dediquei obsessivamente, primeiro como ministro, depois como candidato a presidente" (2010:154). 23

Com bastante franqueza, Fernando Henrique Cardoso assume que foi exatamente a saturação social com a crise econômica que gerou o ambiente político necessário para que reformas profundas institucionais fossem realizadas sob o pretexto de "segurar o real" (2010:155).
} 
constituinte. Não é possível, ainda, analisar se essa situação foi modificada pelos recentes protestos ocorridos ao longo do mês de junho de 2013.

Nesse sentido, a evolução recente da teoria constitucional criada por Bruce Ackerman é bastante relevante para explicar tanto essa conclusão como a proposta que será apresentada em seguida. Segundo o modelo dualista de democracia inicialmente desenvolvido pelo autor ${ }^{24}$, existiriam dois momentos distintos para a tomada de decisões políticas: (a) os momentos constitucionais em que o povo decide e (b) os momentos ordinários em que os detentores do poder político decidem. Apenas os primeiros, extremamente raros, possuiriam o condão de definir a identidade coletiva de cada nação. Além disso, somente nos momentos constitucionais é que os detentores do poder adquiririam legitimidade para tomar decisões realmente constitucionais. As decisões ordinárias tomadas diariamente pelos detentores do poder não se enquadrariam na categoria de momentos constitucionais (1991:06).

Para Ackerman, as seguintes condições devem estar necessariamente presentes para que determinado momento político possa ser qualificado de constitucional: (a) o líder político (ou partido político) autor da proposta deve lograr convencer número extraordinário de cidadãos a levar a iniciativa com a seriedade que normalmente não é conferida à política ordinária cotidiana; (b) os oponentes do líder político (ou partido político) devem receber justa oportunidade para organizar suas próprias forças; (c) o líder político (ou partido político) deve conseguir apoio da maioria dos integrantes da sociedade ao final de processo no qual o conteúdo da proposta é repetidamente discutido.

Na fase mais recente da sua obra, especialmente nos livros The Stakeholder Society (1999, escrito conjuntamente com Anne Alstot) ${ }^{25}$, Voting With Dollars (2002, escrito conjuntamente com Ian Ayres) ${ }^{26}$, Deliberation Day (2004, escrito conjuntamente com James

\footnotetext{
${ }^{24}$ Referido modelo foi desenvolvido pelo autor com o objetivo de criar uma teoria constitucional realmente norte-americana alheia a importações conceituais irrefletidas (1991:06).

${ }^{25}$ A proposta inovadora contida nessa obra é a atribuição de uma quota social de US\$ 80,000.00 (oitenta mil dólares norteamericanos) para todos os cidadãos do país que atingissem a fase inicial da sua vida adulta. As quotas sociais seriam financiadas através da criação de um novo imposto e os beneficiados seriam livres para usar a quantia para o propósito que escolhessem. O objetivo é conferir à população que ingressará no mercado de trabalho certo grau de independência para tomar as suas decisões pessoais e profissionais. A aposta de Ackerman e Alstot é que haverá significativa diminuição no número de jovens literalmente fracassados na sociedade norte-americana (1999:04-05).

${ }^{26}$ Em linhas gerais, a proposta apresentada nesse livro almeja redefinir a lógica de funcionamento das campanhas eleitorais através da atribuição de diferentes quotas políticas ("patriot dolars") para todos os cidadãos com capacidade eleitoral, de modo a que cada um pudesse escolher em qual político ou partido político investir durantes as campanhas (2002:182221).
} 
Fishkin) $)^{27}$ e Decline and Fall of The American Republic (2010) ${ }^{28}$, Ackerman objetivou interferir na agenda dualista do modelo de democracia que desenhou para os Estados Unidos. Nesse sentido, buscou confeccionar experimentos destinados a tornar mais frequente a ocorrência de momentos de interesse social na política assemelhado ao que se verifica nos momentos constitucionais. O caminho encontrado pelo autor foi reinventar mecanismos cívicos com o objetivo de fazer com que o maior número de cidadãos possível dedicasse à cidadania a quantidade de atenção que não emprega na política ordinária cotidiana.

A visão de Ackerman, assumida mais explicitamente em recente artigo intitulado Reviving Democratic Citizenship? (2012), é no sentido de que a significativa maioria das instituições cívicas herdadas pela atual geração norte-americana está morta ou em fase de inanição, sendo que "além do ato formal do voto, o ato mais significante de cidadania [do norte-americano] é mostrar o seu passaporte nas fronteiras" (2012:1). Assim, em avanço à fase inicial mais descritiva da sua obra, o autor passou a produzir textos de cunho propositivo, geralmente sobre temas de ciência política, voltados à criação de uma espécie de "agenda de cidadania" destinada à criação de instituições sociais voltadas ao "exercício da democracia na vida ordinária" dos norte-americanos (2012:1).

Basicamente, o objetivo de Ackerman tem sido gerar não apenas o incremento da consciência cívica das populações, mas, principalmente, o surgimento de "ciclos de virtude" que teriam impacto direto em todas as instituições políticas (2002:75-96). Em última instância, sua agenda de cidadania almeja criar verdadeira esfera pública política/arena do dissenso na sociedade civil norte-americana. Por meio da elaboração imaginativa de distintos canais institucionais de comunicação entre a sociedade civil e as instituições detentoras do poder político, Ackerman tenciona claramente alcançar o objetivo máximo do experimentalismo institucional: aumentar a quantidade de política transformativa produzida cotidianamente.

Com a criação de solidariedade forçada, as inovações institucionais propostas por Ackerman poderão gerar incremento de política transformativa e a própria "revitalização da

\footnotetext{
${ }^{27}$ Esse livro apresenta proposta de criação de feriado nacional financiado pelo Estado que antecederia as eleições presidenciais e teria como objetivo criar espaços destinados exclusivamente à deliberação da sociedade civil acerca das plataformas de campanha dos candidatos (2004:75-96).

${ }^{28}$ Nessa obra, Ackerman propõe a criação de um voucher de notícias jornalísticas na internet. De acordo com a proposta, os usuários da internet seriam sempre convidados a indicar os textos jornalísticos que contribuíram para o incremento da sua compreensão da vida política. Os votos dos usuários da internet seriam transmitidos a uma espécie de agenda reguladora que compensaria financeiramente as organizações de imprensa responsáveis pelos artigos mais votados. A ideia, segundo Ackerman, é semelhante à do dia da deliberação: criar microespaços de discussão política na sociedade civil (2010:133 134).
} 
cidadania democrática" (2012, p. 01). Isso porque, conforme corretamente percebeu o autor, nos momentos de pouco engajamento social na política, é imprescindível o envolvimento direto do Estado no financiamento da cidadania. O laissez-faire estatal com relação à questão tem sido o responsável pelo baixo engajamento da sociedade civil após o desaparecimento dos raros momentos de solidariedade espontânea. O resultado dessa política liberal tem sido o frequente surgimento de esferas públicas políticas fantasmas nas democracias atuais (2004: 193-198).

É difícil fugir à percepção de que o referido raciocínio se amolda à realidade atual da democracia brasileira. Conquanto o voto obrigatório represente importante política de exercício forçado da cidadania no Brasil, é inegável que outros experimentalismos institucionais, como a reinvenção dos serviços sociais forçados, a rediscussão dos mecanismos de financiamento de campanha e de funcionamento dos partidos políticos, assim como o pensamento de novas formas de educação sentimental massificada, poderiam facilitar sobremaneira a aceleração da democracia brasileira atual.

Nesse sentido, embora sejam direcionados à democracia norte-americana, os experimentos sugeridos por Ackerman nas obras anteriormente citadas poderiam ser adaptados à realidade brasileira. Algo assemelhado às quotas sociais, por exemplo, poderia ser estudado no Brasil, assim como a utilização de mecanismo inspirado no Deliberation Day para as eleições municipais. A própria alteração da lógica de financiamento de campanhas atualmente empregada no Brasil é questão que justifica estudo mais aprofundado. A proposta de Ackerman de permitir à população interferir diretamente no mecanismo de divisão das receitas públicas de financiamento das campanhas eleitorais é também bastante interessante como mecanismo de criação de maior identidade ideológica para os partidos políticos no Brasil. Na mesma linha, as facilidades da comunicação por intermédio da internet poderiam ser aproveitadas na criação de arenas cibernéticas institucionalizadas, financiadas e estimuladas pelo Estado, para debates de questões da política cotidiana pelos cidadãos. Seria relevante, ainda, desenvolver tanto mecanismos que estimulassem financeiramente $o$ surgimento de mais projetos de leis de iniciativa popular, como agendas estatais sérias de promoção da cidadania durante os feriados nacionais.

\section{As metamorfoses da democracia: agenda de pensamento teórico}

Encerrada a análise específica da situação atual da democracia brasileira, é 
necessário reconhecer que direcionar o pensamento teórico sobre a democracia para o aumento da participação popular nas decisões políticas é lugar comum sempre que se busca falar em crises de representatividade. Justamente por isso, é fundamental sofisticar a premissa que justifica a defesa de experimentalismos institucionais voltados à superação da política de laissez-faire estatal com relação à promoção da cidadania democrática no Brasil.

Duas questões teóricas são relevantes para esse desenvolvimento: (a) definir uma agenda teórica de trabalho com relação ao momento de metamorfose substantiva no conceito de democracia que parece existir no Brasil hoje; e (b) localizar, dentro dessa agenda, espaço para enfrentamento do problema consistente no papel que deve ser atribuído ao eleitor entre as eleições nos governos representativos.

Em sua obra The Principles of Representative Government, após revelar com precisão o significado e as consequências do princípio da distinção que marca todas as espécies de eleição (2002:94), Bernard Manin assentou a premissa de que "o fato fundamental sobre as eleições é que elas são simultânea e indissoluvelmente iguais e desiguais, democráticas e aristocráticas", sendo que "a dimensão aristocrática merece atenção especial atualmente porque costuma ser esquecida ou atribuída a fatores equivocados" (2002:149150). A partir desse ponto de partida, Manin desenvolveu um modelo ideal de sistema eleitoral, no qual o critério de distinção que representa caráter aristocrático das eleições seria deixado à livre escolha do eleitor. Desse modo, mesmo não sendo todos os cidadãos aptos na prática a serem selecionados como representantes, em razão da inafastabilidade do princípio da distinção, haveria equilíbrio institucional no pleito eleitoral, de modo que "qualquer indivíduo poderia parecer superior aos outros por algum critério" (2002:158). Nesse modelo, a escolha pelo conteúdo do princípio de distinção seria deixada aos eleitores, de modo a neutralizar os desequilíbrios democráticos inerentes à dimensão aristocrática que não pode ser afastada das eleições. A proposta de Manin, dessa maneira, deixa ao eleitor a escolha do tipo de aristocracia que irá representá-lo ${ }^{29}$.

Ao tratar das diversas metamorfoses que o governo representativo passou desde o final do século XVIII, Manin deixa claro, inicialmente, que "o que hoje se entende por democracia representativa tem as suas origens em sistemas de instituições (estabelecidos no despertar das revoluções inglesa, americana e francesa) que, de maneira alguma, foram

\footnotetext{
${ }^{29}$ Essa questão fica bastante clara na seguinte afirmação de Manin: “Em sistemas eletivos a única dúvida possível diz respeito ao tipo de superioridade que irá marcar os governantes. Quando for indagado sobre quem devem ser os aristocratas a governar, o defensor da democracia deve se virar para o povo e deixa-lo decidir" (2002:160).
} 
inicialmente concebidos como formas de democracia ou de governo pelo povo" (2002:1). O autor retira essa conclusão não apenas dos modelos institucionais ou consuetudinários de distinção aristocrática entre eleitos e eleitores existentes na França, na Inglaterra ou nos Estados Unidos no final do século XVIII (2002:94-131), mas também dos próprios ensinamentos de teóricos clássicos do governo representativo, como Rosseau, Madison e Siéyès. Nesse sentido, comprovou que o fundamento da representação, tal como foi inicialmente concebida nesses países, era justamente selecionar os mais ricos como governantes. Segundo Manin, foram necessárias metamorfoses inesperadas para que o governo representativo se aproximasse da democracia atual, tais como o surgimento do sufrágio universal e de partidos políticos ${ }^{30}$ (2002:194).

Especificamente em relação aos partidos políticos, após apontar autores que viam esse desenvolvimento das democracias como evidência de crise da representatividade política, Manin defendeu exatamente o oposto, por entender que "os partidos aproximaram os representantes das suas comunidades, fazendo com que fosse possível a indicação de candidatos cuja posição social, estilo de vida e preocupações fossem próximos aos daqueles pertencentes às camadas mais pobres da sociedade" (2002:195-196).

A metamorfose mais recente dos governos representativos foi caracterizada por Manin com expressão "democracia de audiência". Esse momento, identificado pelo autor como fenômeno iniciado a partir da década de 1970, teria representado retrocesso democrático por transformar indivíduos em instituições mais importantes do que os partidos políticos. A partir de então, as campanhas políticas e os próprios partidos políticos teriam voltado suas atenções à figura de um determinado líder. Para Manin, ainda que "os partidos desempenhem um papel central nesse cenário", fornecendo instrumental financeiro e físico, “eles se tornaram instrumentos a serviço de um líder" (2002:219).

Duas causas foram apontadas por Manin como determinantes para a ocorrência dessa última metamorfose: (a) o incremento da comunicação política por intermédio de canais de rádio e televisão, o que conferiu maior destaque à individualidade dos candidatos do que às particularidades da sua plataforma política; e (b) o aumento da complexidade da atividade política, que fez com que os representantes eleitos tivessem que lidar diariamente com uma

\footnotetext{
${ }^{30}$ Especificamente com relação ao surgimento dos partidos políticos e da oposição como desenvolvimentos inesperados dos governos representativos, vale conferir a análise de Richard Hofstadter, na obra The Ideia of a Party System: The Rise of Legitimate Opposition in the United States, 1780-1840. A síntese do pensamento de Hofstadter é a de que, nos Estados Unidos, "primeiro os partidos políticos precisaram ser criados; mais tarde, apenas, começaram a encontrar aceitação teórica" (1997:39).
} 
série de decisões a respeito de questões que não poderiam ser previstas com antecedência, tornando literalmente impossível, para o eleitor, escolher um candidato a partir de critérios seguros com relação ao mérito das preferências deste (2002:220). Ambas as características, segundo Manin, fizeram com que as peculiaridades individuais dos candidatos se sobressaíssem às distinções ideológicas dos partidos políticos. Por consequência, a confiança pessoal inspirada por cada candidato e a sua habilidade para lidar com exposições públicas teriam se tornado o principal fator de desequilíbrio eleitoral desde então.

O problema dessa metamorfose, para Manin, que é o que qualifica a democracia atual como uma "democracia de audiência", é o fato de que, nesse cenário, os eleitores tendem a "responder" a estímulos que surgem no curso dos processos eleitorais, no lugar de "expressar" as suas reais preferências. Atualmente, o voto passou a ser reativo à iniciativa dos próprios candidatos, fazendo com que o "eleitorado apareça, acima de tudo, como uma audiência que responde aos termos daquilo que foi apresentado no palco político" (2002:223). Isso não significa, contudo, que os políticos tenham ganhado total liberdade para inventar as bases da clivagem. Conforme reconhece Manin, "os políticos podem tomar a iniciativa da propositura de um princípio de divisão do eleitorado, (...) mas não têm condições de saber, de antemão, qual será o critério de clivagem mais efetivo" (2002:224).

$\mathrm{O}$ que poderia ser diagnosticado com uma nova crise da representatividade dentro da democracia de audiência é explicado por Manin como o surgimento de uma nova elite aristocrática nas eleições, no lugar da anterior. Assim, o princípio da distinção permaneceria presente nas democracias de audiência, embora estruturado segundo lógica distinta.

Além disso, o rumo positivo dos governos representativos também teria sido alterado com o surgimento das democracias de audiência. Segundo Manin, quando os "ativistas políticos e os burocratas tomaram o lugar dos notáveis, a história pareceu diminuir o espaço existente entre as elites governantes e os cidadãos ordinários". Contudo, para Manin, "não há razão para se pensar que as elites políticas e midiáticas atuais são mais próximas dos eleitores do que os antigos burocratas partidários". Assim, ao invés de representar apenas a substituição de uma elite por outra, a democracia de audiência poderia significar, na visão do autor, o "agravamento da distância entre os governados e os representantes" (2002:233). Portanto, ainda que o governo representativo tenha inquestionavelmente se democratizado desde o seu surgimento, consoante Manin “a diminuição da distância entre governantes $e$ 
governados e o aumento da influência dos governados sobre os governantes se revelaram fenômenos menos duradouros do que o esperado" (2002:234).

Conquanto não seja possível explicar o momento atual da democracia brasileira apenas a partir da explicação da crise de representatividade diagnosticada por Manin, é relevante perceber, a partir dessas considerações, que:

(a) não é possível recuperar a legitimidade democrática original supostamente perdida do governo representativo. Pelo contrário, é necessário reconhecer que foram justamente os desdobramentos teóricos inesperados dos governos representativos que os aproximaram daquilo que hoje entendemos por democracia, especialmente a partir do momento em que surgiram os partidos políticos;

(b) justamente por isso, não é recomendável tratar o problema da aparente crise de legitimidade da democracia brasileira a partir de bases niilistas, como aquelas que pregam o ingênuo repúdio abstrato aos partidos políticos. O caráter aristocrático das eleições tende apenas a ser majorado quando a opção institucional é direcionada a arranjos que apenas fomentam princípios de distinção pautados no poder econômico, que é o que historicamente ocorreu antes do surgimento dos partidos políticos; e

(c) o momento aparentemente transicional da democracia brasileira demanda experimentalismos institucionais voltados, na medida do possível, ao alcance da lógica do modelo ideal preconizado por Manin, quando é deixada ao eleitor a liberdade de escolha do princípio da distinção que irá definir a composição da aristocracia representativa.

A partir dessas conclusões, torna-se fácil perceber que a pergunta relacionada ao papel do eleitor entre as eleições ganha relevância. Pode ser que o aumento da dimensão ativa do cidadão na política represente caminho de diminuição do retrocesso representativo criado no momento atual das democracias de audiência. A agenda de pensamento teórico, nesse sentido, pode iniciar-se pela premissa colocada por Ackerman no sentido de que a cidadania democrática deve ser revitalizada a partir de políticas estatais indutoras.

\section{Referências bibliográficas}

ACKERMAN, Bruce. We the People: Foundations. Cambridge \& London: Harvard University Press, 1991. 
Press, 1999.

; STOLT, Anne. The Stakeholder Society. New Haven \& London: Yale University

; AYRES, Ian. Voting with Dollars: A New Paradigm for Campaign Finance. New

Haven \& London: Yale University Press, 2002.

; FISHKIN, James S. Deliberation Day. New Haven \& London: Yale University Press, 2004.

The Decline and Fall of The American Republic. Cambridge \& London: Harvard University Press, 2010.

Reviving Democratic Citizenship? Artigo apresentado na sessão de 18.12.2012 da American Sociological Association.

BARBOSA, Leonardo Augusto de Andrade. Mudança constitucional, autoritarismo e democracia no Brasil pós-1964. Tese de doutorado defendida perante a Faculdade de Direito da Universidade de Brasília em 2009. Disponível em: http://repositorio.bce.unb.br/handle/10482/4075.

CARDOSO, Fernando Henrique. Relembrando o que escrevi: da reconquista da democracia aos desafios globais. Rio de Janeiro: Editora Civilização Brasileira, 2010.

. Xadrez internacional e social-democracia. Editora Paz e Terra, 2010.

2012.

A arte da política: a história que vivi. Rio de Janeiro: Editora Civilização Brasileira,

HABERMAS, Jürgen. Direito e democracia: entre facticidade e validade. Volume I, $2^{\mathrm{a}}$ Ed., Tradução: Flávio Beno Siebeneichler, Rio de Janeiro: Tempo Brasileiro, 2003a.

Direito e democracia: entre facticidade e validade. Volume II, $2^{\mathrm{a}}$ Ed., Tradução: Flávio Beno Siebeneichler, Rio de Janeiro: Tempo Brasileiro, 2003b.

HOFSTADTER, Richard. The idea of a party system: the rise of legitimate opposition in the United States, 1780-1840. Los Angeles: University of California Press, 1997.

JOBIM, Nelson. A Constituinte vista por dentro - vicissitudes, superação e efetividade de uma história real, in: SAMPAIO, José Adércio Leite (coord.). Quinze anos de Constituição. Belo Horizonte: Del Rey, 2004, p. 917.

MANIN, Bernard. The principles of representative government. New York: Cambridge University Press, 1997.

NEVES, Marcelo. Entre Têmis e Leviatã: uma relação difícil. 2a Ed., São Paulo: Martins Fontes, 2008. 
PRZEWORSKI, Adam. Democracy and the limits of self-government. New York: Cambridge University Press, 2010.

TILLY, Charles. Democracy. New York: Cambridge University Press, 2007.

UNGER, Roberto Mangabeira. Política: os textos centrais. $1^{\text {a }}$ Ed., Rio de Janeiro: Boitempo, 2001.

. O direito e o futuro da democracia. $1^{\text {a }}$ Ed., Rio de Janeiro: Boitempo, 2004a.

False necessity: Anti-necessitarian social theory in te servisse of radical democracy

- Volume 1 of Politics. New Edition, New York: Verso, 2004b.

. Social theory: its situation and its task - Volume 2 of Politics. New Edition, New York: Verso, 2004c.

. Plasticity into power: comparative-historical studies on the institutional conditions of economic and military success - Volume 3 of Politics. New Edition, New York: Verso, 2004d.

Artigo recebido em 03 de outubro de 2013. Artigo aprovado para publicação em 17 de outubro de 2013.

DOI: $10.11117 / 1982-4564.06 .15$ 